\title{
Prevalence of Obstructive Sleep Apnea Among Saudi Pilots
}

\author{
Faris Alhejaili ${ }^{\prime}$ \\ Afnan Hafez (D) ${ }^{2}$ \\ Siraj Wali iD ' \\ Ranya Alshumrani' \\ Ahmed M Alzehairi ${ }^{3}$ \\ Mansour Balkhyour ${ }^{4}$ \\ Seithikurippu R Pandi- \\ Perumal (iD ${ }^{5}$ \\ 'Sleep Medicine Research Group, Sleep \\ Medicine and Research Center, King \\ Abdulaziz University Hospital, Jeddah, \\ Saudi Arabia; ${ }^{2}$ Pulmonary Medicine \\ Consultant, Sleep Medicine Specialist, \\ Researcher at Sleep Medicine and \\ Research Center, King Abdulaziz \\ University Hospital, Jeddah, Saudi Arabia; \\ ${ }^{3}$ Environmental Sciences, Faculty of \\ Environmental Sciences, King Abdulaziz \\ University, Jeddah, Saudi Arabia; ${ }^{4}$ Faculty \\ of Environmental Sciences, King \\ Abdulaziz University, Jeddah, Saudi \\ Arabia; ${ }^{5}$ Somnogen Canada Inc., Toronto, \\ Ontario, M6H IC5, Canada
}

Purpose: To evaluate the presence of obstructive sleep apnea (OSA), using home sleep testing in pilots and first officers in Saudi-based airlines. This will allow for proper diagnosis and management of OSA in that group which can help in minimizing any possible aviation accidents related to sleep disturbances secondary to OSA.

Materials and Methods: This is a cross-sectional study conducted through Saudi-based aviation among pilots and first officers who were in service, active, and flying short- to medium-haul flights. Forty-one participants met the inclusion criteria. However, 39 out of 41 completed the study questionnaires (Berlin questionnaire, Epworth sleepiness scale, Pittsburgh sleep quality index (PSQI), Fatigue severity scale (FSS), Visual analog fatigue scale (VAFS), and Patient health questionnaire (PHQ9), along with home sleep testing.

Results: Sixty-nine percent of the study population had OSA by home sleep testing. Majority of which had mild OSA (64\%) and 5\% had moderate and severe OSA $(2.5 \%$ each). Results of different questionnaires showed one-third of the participants had insomnia, $33.3 \%$ of the participants had severe fatigue, excessive daytime sleepiness was found in $23.1 \%$ of the participants, and $10.3 \%$ had moderate depression, while $25.6 \%$ were classified as having mild depression symptoms.

Conclusion: Sleep apnea is prevalent among the studied Saudi-based airline pilots and first officers. Screening for workers of this high-risk occupation needs to be considered. Fatigue, depression, and insomnia can be secondary consequences of sleep apnea and should be assessed and treated early.

Keywords: sleep apnea, insomnia, fatigue, depression, pilots, aviation

\section{Plain Language Summary}

Obstructive sleep apnea (OSA) is a common problem that affects a person's breathing during sleep, during which air cannot flow normally into the lungs. The blockage in the airflow is usually caused by the collapse of the soft tissues in the back of the throat (upper airway) and the tongue during sleep.

In this study, we tested 39 participants including pilots and first officers in Saudi air line-based aviation services to see if they have any apneas during sleep. They also filled few questionnaires that provide a screening for the risk and consequences of sleep problems.

Results showed that $64 \%$ had mild OSA (which means 5-14 events per hour of sleep), $2.5 \%$ had moderate (15-30 per hour of sleep), and 2.5\% had severe OSA ( $>30$ events per hour of sleep).

One-third of participants had some problems initiating or maintaining sleep (insomnia),33\% had tiredness and fatigue,35.9\% had depression, while $23.1 \%$ were excessively sleepy during the daytime. 
We concluded that sleep apnea is common among pilots and first officers, and we strongly advice for early detection of those at high risk and treat them to prevent its complications and consequences.

\section{Introduction}

Air travel has become the main method of transportation in the modern era. It is the fastest and most efficient mode of transportation around the globe. Concurrent with the expansion of the aviation industry, there has been an increase in concern about the health of aircrew members and the safety of both passengers and aircrew members. There is a growing need to detect and prevent various adverse physiological responses to physical stresses encountered in the aerospace environment. Many aviation accidents were reported to be secondary to human factors that could have been prevented. Human factors, including issues such as fatigue, loss of situational awareness and sleepiness, can play a crucial role in accidents that could lead to a tragic loss of life. A report from the National Transportation Safety Board (NTSB) stated that "drowsy flying can be as deadly as drowsy driving" after investigating a plane crash in February 2013. ${ }^{1}$

The NTSB determined that obstructive sleep apnea (OSA) was a factor contributing to the February 13, 2008, Mesa Airlines Flight 1002 incident. Both the captain and the first officer fell asleep during the flight. The captain was found to have undiagnosed severe OSA. The NTSB database lists 34 accidents - 32 of which were fatal - in which sleep apnea was mentioned in the pilot's medical history, although sleep apnea was not listed as "causal" or "contributory" with regard to those accidents. The database includes an additional 294 incidents in which some type of sleep disorder was mentioned in the pilot's history. $^{2}$

Unfortunately, aircrew members are at high risk of having sleep disorders. ${ }^{3}$ They are forced to cope with very early and very late flights, crossing different time zones, and sleep deprivation. These disorders can lead to fatigue and increase medical and mental health complications. ${ }^{4}$ Moreover, the prevalence of obesity is high among commercial airline pilots and constitutes a public health problem in this population. Excess weight has been found to be associated with working night shifts, difficulty relaxing after work, inadequate sleep on days off, having other chronic diseases, and physical inactivity. ${ }^{5}$

Sleep disorders are common. Given the rate of increase in obesity, the prevalence of sleep disorders is expected to continue to increase in the coming decades. In Saudi Arabia, the prevalence of OSA is estimated to be $8.8 \%$ ( $12.8 \%$ in men, $5.1 \%$ in women) according to a study by Wali et $\mathrm{al}^{6}$ However, the prevalence of OSA among Saudi pilots has not yet been objectively studied.

A few studies worldwide have highlighted the prevalence of the complications of sleep disturbance, such as fatigue and excessive daytime sleepiness, in aircrew members. In Portugal, Reis et $\mathrm{al}^{3}$ concluded that among pilots, the prevalence of sleep complaints, excessive daytime sleepiness, and fatigue was $34 \%, 53 \%$, and $90.6 \%$, respectively, especially among those on short- and medium-haul flights.

A recent study performed by Aljurf et $\mathrm{al}^{7}$ assessed the prevalence of fatigue, depression, and sleepiness and the risk of OSA among commercial airline pilots in the Gulf region. They found that $34.1 \%$ of the pilots had an ESS score $\geq 10$, indicating excessive daytime sleepiness; $34.5 \%$ of the pilots had an abnormal HADS depression score; and $29.3 \%$ were at high risk for OSA and needed further assessment. $^{7}$

A position paper published in 2015 stated that commercial pilots may be at risk for OSA, making screening for OSA an urgent flight safety issue. The Aerospace Medical Association encourages any initiatives that enhance awareness and lead to the treatment of this condition because it affects flight safety and pilot performance. $^{5}$

Many patients, including pilots, are unaware of having sleep disturbances, and the symptoms are not easily recognizable. Pilots suffering from OSA do not necessarily have to lose their license. Diagnosis and treatment, with regular check-ups, can be recommended instead. Panton et $\mathrm{al}^{8}$ even suggested that questions about sleep need to be included in routine pilot health examinations.

There is a lack of studies addressing different sleeprelated disorders in pilots and other aircrew members in Saudi-based airlines. In this study, we objectively evaluated OSA to improve early detection and treatment to minimize airplane accidents secondary to human factors related to this condition.

\section{Materials and Methods Research Design}

This was a cross-sectional study conducted through Saudibased aviation services in collaboration with the sleep medicine department and a research center at King 
Abdulaziz University Hospital targeting pilots and first officer. The target sample size was 46 participants.

\section{Target Population}

Active airline pilots working for a Saudi-based airline constituted the study population. This study targeted narrow-bodied aircraft (Airbus A-320) pilots and first officers who were flying short- to medium-haul flights. As there was more than one category of pilots in service, only active and regular pilots were included.

The other categories of A-320 pilots, such as management pilots, instructor pilots (IPs), and check pilots or check airmen, were excluded. Pilots who were undergoing training (initial, transition, upgrade, and/or requalification) were also excluded from participating in this study.

The total number of potential participants was 46 . Among these, 41 participants met the inclusion criteria. However, only thirty-nine (39) pilots agreed to participate in the study. All participants were asked to fill out the related questionnaires, and they were assured of the confidentiality of their responses and the results of testing; this was accomplished by sending a copy of the questionnaires by mail with clear instructions and assurances. Then, paper questionnaires were distributed by the fleet manager's office to ensure confidentiality.

\section{Questionnaires}

\section{Demographics and Professional Characteristics}

Age and nationality were the demographic variables assessed. The professional characteristics were as follows: rank, type of pairing, type of flight, number of take-offs (TOs) and landings per month, duty time, and timing of flight (day or night).

\section{Berlin Questionnaire}

The risk of sleep apnea was assessed with the Berlin questionnaire, which has 3 sections. ${ }^{9,10}$ The patient was considered at high risk if they had positive scores in at least 2 sections.

\section{Epworth Sleepiness Scale}

Daytime sleepiness in 8 different daily situations was assessed with this scale; the probability of falling asleep in each situation was rated on a scale from 0 to 3 . Scores of 10 or greater were considered abnormal. ${ }^{11}$

\section{Pittsburgh Sleep Quality Index (PSQI)}

Sleep quality was assessed over a 1-month period with the PSQI. ${ }^{12}$ The questionnaire is composed of 19 individual items divided into 7 components: subjective sleep quality, sleep latency, sleep duration, habitual sleep efficiency, sleep disturbances, use of sleep medications and daytime dysfunction. A score for each component is obtained and summed to yield the global PSQI score. A total score of 5 or greater is indicative of poor sleep quality.

\section{Fatigue Severity Scale (FSS)}

The FSS is a validated self-reported fatigue questionnaire with nine questions assessing the prevalence of severe fatigue. Severe fatigue was indicated by a score $\geq 36 .{ }^{13}$

\section{Visual Analog Fatigue Scale (VAFS)}

Traditionally, a visual analog scale (VAS) consists of a 10$\mathrm{cm}$ horizontal line with written descriptions at each end; subjects are asked to mark on the line the point that they feel represents their current state. ${ }^{14}$ The possible score ranges from 0 to 100 , measured in millimeters on the 10 $\mathrm{cm}$ vertical line. In this study, the score was obtained by measuring the line from "No Fatigue" to the point indicated by the subject as representative of their fatigue level; the higher the VAFS score was, the more fatigued the pilot.

\section{Patient Health Questionnaire (PHQ9)}

The PHQ is a tool used to screen for major depressive disorder. It consists of 9 questions, each of which is scored from 0 to $3 .{ }^{15}$ Patients who score less than 4 are unlikely to have depression. The lowest possible score is 0 , and the highest is 27. Higher scores suggest more severe depression.

\section{Procedure Details}

After completing the questionnaires, a home sleep apnea test (HSAT) was conducted for all participants. The HSAT was performed using the SOMNOtouch ${ }^{\mathrm{TM}}$ system (Somnomedics GmbH, Randersacker, Germany), which has the following integrated sensors: flow and snoring (nasal cannula), thorax and abdomen effort, $\mathrm{SpO} 2$, pulse rate, body position, and movement (for sleep/wake time estimations). It also has external sensors (AUX connections for extended recordings, eg, periodic leg movements (PLMs), electrocardiogram (ECG), electroencephalogram (EEG), electrooculography (EOG), and electromyography $(\mathrm{EMG})){ }^{16}$

The HSAT was performed at the participants' homes. All participants were interviewed individually prior to the sleep study and were trained how to apply and disconnect the SOMNOtouch ${ }^{\mathrm{TM}}$ system. HSAT records were collected 
and scored in accordance with the technical guidelines for scoring and staging sleep based on the updated American Academy of Sleep Medicine (AASM) Scoring Manual 2018 version 2.5. ${ }^{17}$

Abnormal obstructive breathing events that were recorded were scored according to the latest recommendation of the AASM as follows: a decrease in airflow by $90 \%$ or more from baseline for at least 10 seconds was scored as apnea, while hypopnea was defined by a reduction in airflow of at least $30 \%$ from the baseline according to nasal pressure in addition to a reduction in oxygen saturation of at least 3\% and/or subsequent EEG arousal despite the movement of chest and abdominal muscles in an attempt to overcome the obstruction. ${ }^{17}$ EEG arousal was defined according to the recommendations of the AASM. (AASM manual 2018 version 2.5). The average number of these apnea and hypopnea events per hour of sleep (ie, the apnea-hypopnea index [AHI]) was then calculated.

Subjects with an AHI score $\geq 5$ were categorized as having OSA. ${ }^{18}$

The severity classifications used were mild $(\mathrm{AHI}=$ 5-14), moderate $(\mathrm{AHI}=15-30)$, and severe $(\mathrm{AHI}>30) .{ }^{19}$

\section{Analysis}

Statistical analyses were performed using Statistical Package for the Social Sciences (SPSS) version 22. Categorical variables were summarized and are presented in tables. Numerical variables are represented as the means and standard deviations and were assessed with unpaired Student's $t$-tests, linear correlation coefficients, analysis of variance [ANOVA], chi-square tests, and logistic regression. The results were considered significant if the calculated $\mathrm{p}$ values were less than 0.05 .

\section{Results}

In total, 39 participants agreed to undergo the HSAT. This sample population included both captains (48.7\%) and first officers (51.3\%). The mean age and BMI were $43.26 \pm 9.49$ years and $24.47+2.418 \mathrm{~kg} / \mathrm{m}^{2}$, respectively (Table 1 ).

The workload and experience variables are summarized in Tables 1; 59\% of the participants had more than 15 years of experience. The majority of the participants performed 30-40 TOs and landings per month. The flights included both domestic and international flights for approximately $92.3 \%$ of the participants.
Table I Demographic Data and Work Characteristics of the Study Sample

\begin{tabular}{|c|c|c|}
\hline SOMNOtouch & $\mathbf{N}$ & $\%$ \\
\hline \multicolumn{3}{|l|}{ Nationality } \\
\hline Saudi & 7 & $17.9 \%$ \\
\hline Non-Saudi & 32 & $82.1 \%$ \\
\hline \multicolumn{3}{|l|}{ Rank } \\
\hline Captain & 19 & $48.7 \%$ \\
\hline First Officer & 20 & $51.3 \%$ \\
\hline \multicolumn{3}{|l|}{ Experience, years } \\
\hline$<5$ & 3 & $7.7 \%$ \\
\hline $5-10$ & 7 & $17.9 \%$ \\
\hline $10-15$ & 6 & $15.4 \%$ \\
\hline$>15$ & 23 & $59.0 \%$ \\
\hline Range & \multicolumn{2}{|c|}{$3-19$} \\
\hline Mean $\pm S D$ & \multicolumn{2}{|c|}{$14.436 \pm 5.097$} \\
\hline \multicolumn{3}{|l|}{ Age } \\
\hline Less than 30 years & 2 & $5.1 \%$ \\
\hline $30-40$ years & 16 & $41.0 \%$ \\
\hline $40-50$ years & 10 & $25.6 \%$ \\
\hline More than 50 years & 11 & $28.2 \%$ \\
\hline Range & \multicolumn{2}{|c|}{$27-59$} \\
\hline Mean $\pm S D$ & \multicolumn{2}{|c|}{$43.256 \pm 9.499$} \\
\hline \multicolumn{3}{|l|}{ Number of TOs and Landings/Month } \\
\hline$<30$ & 3 & $7.7 \%$ \\
\hline $30-35$ & 19 & $48.7 \%$ \\
\hline $35-40$ & 15 & $38.5 \%$ \\
\hline $40-45$ & 2 & $5.1 \%$ \\
\hline$>45$ & 0 & $0.0 \%$ \\
\hline Range & \multicolumn{2}{|c|}{$26-40$} \\
\hline Mean $\pm S D$ & \multicolumn{2}{|c|}{$33.82 I \pm 3.308$} \\
\hline \multicolumn{3}{|l|}{ Typical pairing } \\
\hline Domestic pairing & 3 & $7.7 \%$ \\
\hline International pairing & 0 & $0.0 \%$ \\
\hline Mixed pairing (domestic and international) & 36 & $92.3 \%$ \\
\hline \multicolumn{3}{|l|}{ Typical daily duty time } \\
\hline Less than 8 hours & 13 & $33.3 \%$ \\
\hline $8-14$ hours & 16 & $41.0 \%$ \\
\hline More than 14 hours & 10 & $25.6 \%$ \\
\hline \multicolumn{3}{|l|}{ Number of sectors/Day } \\
\hline 2 Sectors/day & 1 & $2.6 \%$ \\
\hline 3 Sectors/day & 0 & $0.0 \%$ \\
\hline More than 3 sectors/day & 38 & $97.4 \%$ \\
\hline \multicolumn{3}{|l|}{ Timing of Flight } \\
\hline Day & 0 & $0.0 \%$ \\
\hline Night & 0 & $0.0 \%$ \\
\hline Both & 39 & $100.0 \%$ \\
\hline
\end{tabular}

(Continued) 
Table I (Continued).

\begin{tabular}{|l|c|c|}
\hline SOMNOtouch & N & $\%$ \\
\hline BMI & \\
Range & $19.0-29.39$ \\
Mean \pm SD & $24.47+2.418$ \\
\hline
\end{tabular}

The Berlin questionnaire was used to assess the risk of OSA, and further analysis was performed to evaluate different risk factors for OSA, including age, rank, experience, number of TOs and landing/month, typical pairing, duty times, and number of sectors per day. However, none of these factors were associated with an increased risk of OSA in our study population (Table 2).

Based on the Berlin questionnaire, $5.1 \%$ of the participants were categorized as being at high risk for OSA (Figure 1). However, based on the objective HSAT, a total of $69.2 \%$ of the pilots were found to have OSA (Table 3).
The mean total sleep time was approximately 5 hours, and the majority of participants (79.5\%) had normal sleep efficiency.

According to the AHI results, 25 (64\%) participants had mild OSA, $1(2.5 \%)$ had moderate OSA and $1(2.5 \%)$ had severe OSA (Table 3).

The results of different questionnaires used to assess the relevant characteristics of the participants' sleep history, eg, insomnia, fatigue, depression and quality of sleep, are shown in Figure 1. One-third of the participants had insomnia according to the Athens insomnia scale (AIS). Regarding fatigue, the FSS showed that $33.3 \%$ of the participants had severe fatigue (score $>36$ ), while $23 \%$ scored less than 5 on the VAFS (with zero being worst and 10 indicating a normal state). Excessive daytime sleepiness was found in $23.1 \%$ of the participants. The majority of participants $(64.1 \%)$ had no or minimal depression. Only $10.3 \%$ had moderate depression, while $25.6 \%$ were

Table 2 Correlations Between Demographic Data, Including Work Characteristics, and the Risk of Sleep Apnea According to the Berlin Questionnaire

\begin{tabular}{|c|c|c|c|c|c|c|c|c|c|}
\hline \multicolumn{2}{|l|}{ Demographic Data } & \multicolumn{6}{|c|}{ Berlin Questionnaire Score } & \multirow{2}{*}{\multicolumn{2}{|c|}{ Chi-Square }} \\
\hline & & \multicolumn{2}{|c|}{ Low Risk } & \multicolumn{2}{|c|}{ High Risk } & \multicolumn{2}{|c|}{ Total } & & \\
\hline & & $\mathbf{N}$ & $\%$ & $\mathbf{N}$ & $\%$ & $\mathbf{N}$ & $\%$ & $\mathbf{X}^{2}$ & P-value \\
\hline \multirow[t]{2}{*}{ Rank } & Captain & 17 & $45.9 \%$ & 2 & $100.0 \%$ & 19 & $48.7 \%$ & 2.990 & 0.084 \\
\hline & First Officer & 20 & $54.1 \%$ & 0 & $0.0 \%$ & 20 & $51.3 \%$ & & \\
\hline \multirow[t]{4}{*}{ Experience, years } & $<5$ & 3 & $8.1 \%$ & 0 & $0.0 \%$ & 3 & $7.7 \%$ & 2.187 & 0.534 \\
\hline & $5-10$ & 7 & $18.9 \%$ & 0 & $0.0 \%$ & 7 & $17.9 \%$ & & \\
\hline & $10-15$ & 6 & $16.2 \%$ & 0 & $0.0 \%$ & 6 & $15.4 \%$ & & \\
\hline & $>15$ & 21 & $56.8 \%$ & 2 & $100.0 \%$ & 23 & $59.0 \%$ & & \\
\hline \multirow[t]{4}{*}{ Age } & Less than 30 years & 2 & $5.4 \%$ & 0 & $0.0 \%$ & 2 & $5.1 \%$ & 5.346 & 0.148 \\
\hline & $30-40$ years & 16 & $43.2 \%$ & 0 & $0.0 \%$ & 16 & $41.0 \%$ & & \\
\hline & $40-50$ years & 10 & $27.0 \%$ & 0 & $0.0 \%$ & 10 & $25.6 \%$ & & \\
\hline & More than 50 years & 9 & $24.3 \%$ & 2 & $100.0 \%$ & 11 & $28.2 \%$ & & \\
\hline Number of TOs and Landings/ & $<30$ & 3 & $8.1 \%$ & 0 & $0.0 \%$ & 3 & $7.7 \%$ & 2.990 & 0.393 \\
\hline \multirow[t]{3}{*}{ Month } & $30-35$ & 17 & $45.9 \%$ & 2 & $100.0 \%$ & 19 & $48.7 \%$ & & \\
\hline & $35-40$ & 15 & $40.5 \%$ & 0 & $0.0 \%$ & 15 & $38.5 \%$ & & \\
\hline & $40-45$ & 2 & $5.4 \%$ & 0 & $0.0 \%$ & 2 & $5.1 \%$ & & \\
\hline \multirow[t]{2}{*}{ Typical pairing } & Domestic pairing & 3 & $8.1 \%$ & 0 & $0.0 \%$ & 3 & $7.7 \%$ & 0.329 & 0.566 \\
\hline & $\begin{array}{l}\text { Mixed pairing (domestic and } \\
\text { international) }\end{array}$ & 34 & $91.9 \%$ & 2 & $100.0 \%$ & 36 & $92.3 \%$ & & \\
\hline \multirow[t]{3}{*}{ Typical daily duty time } & Less than 8 hours & 12 & $32.4 \%$ & 1 & $50.0 \%$ & 13 & $33.3 \%$ & 1.245 & 0.537 \\
\hline & 8-14 hours & 15 & $40.5 \%$ & 1 & $50.0 \%$ & 16 & $41.0 \%$ & & \\
\hline & More than 14 hours & 10 & $27.0 \%$ & 0 & $0.0 \%$ & 10 & $25.6 \%$ & & \\
\hline \multirow[t]{2}{*}{ Number of sectors/day } & 2 Sectors/Day & 1 & $2.7 \%$ & 0 & $0.0 \%$ & 1 & $2.6 \%$ & 0.107 & 0.744 \\
\hline & More than 3 sectors/day & 36 & $97.3 \%$ & 2 & $100.0 \%$ & 38 & $97.4 \%$ & & \\
\hline
\end{tabular}




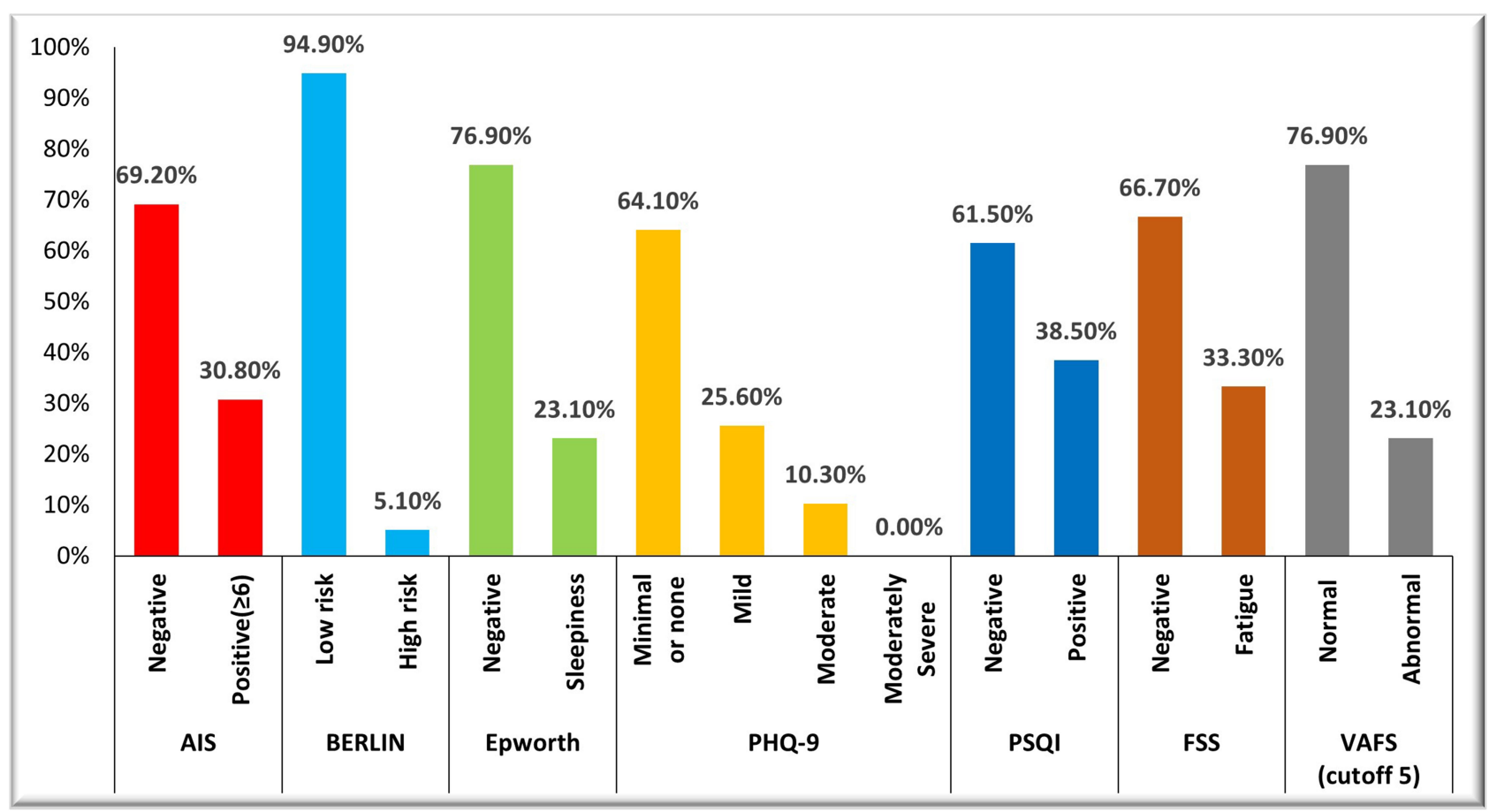

Figure I Characteristics of sleep history among the study sample.

classified as having mild depression. Sleep quality was suboptimal in $38.5 \%$ of the study population.

No correlation between the AHI score and BMI was found in our study. However, the correlation between the number of desaturations per hour and BMI was statistically significant, with a $\mathrm{p}$ value of 0.05 .

Duty time (less than $8 \mathrm{~h}, 8-14 \mathrm{~h}$, more than $14 \mathrm{~h}$ ) was not associated with the sleep study parameters, eg, total sleep duration, sleep efficiency, AHI score, and number of desaturations.

\section{Discussion}

Although the aviation industry is growing worldwide, research on OSA among aircrew members is still lacking

Table 3 Sleep Study Parameters

\begin{tabular}{|l|l|c|c|c|c|}
\hline \multicolumn{2}{|l|}{ SOMNOtouch } & \multicolumn{2}{|c|}{ Group III } & \multicolumn{2}{c|}{ Score } \\
\cline { 3 - 6 } & N & $\%$ & Range & Mean士SD \\
\hline $\begin{array}{l}\text { Sleep efficiency } \\
\text { (cutoff 75\%) }\end{array}$ & Normal & 31 & 79.5 & $21-95$ & $79.133 \pm 16.035$ \\
\hline AHI & Nonormal & 8 & 20.5 & & \\
& Mormal & 12 & 30.77 & $0.4-38$ & $8.051 \pm 6.28$ I \\
& Moderate & I & 64.10 & & \\
& Severe & I & 2.56 & & \\
& & & & \\
\hline
\end{tabular}

Abbreviations: $\mathrm{AHI}$, apnea-hypopnea index. and has not kept pace with expansion in this field. To our knowledge, this is the first study to objectively evaluate the prevalence of OSA among captains and first officers in Saudi-based aviation services. Although the results of the Berlin questionnaire indicated that only $5.1 \%$ of pilots were at high risk of OSA, $69.2 \%$ of pilots had sleep apnea when evaluated objectively with the HSAT.

The sensitivity and specificity of the Berlin questionnaire for the diagnosis of OSA based on an AHI cutoff of 5 were $77.3 \%$ and $23.1 \%$, respectively, with a positive predictive value of $68.0 \%$ and a negative predictive value of $22.0 \%{ }^{20}$ Nevertheless, in our study, there was a substantial discrepancy between the estimated risk and the actual detection of OSA.

This observation could be related to a lack of awareness or underestimation of snoring, fatigue and daytime sleepiness. Moreover, this underestimation could be due to the desire to avoid jeopardizing their job if they admit or report having sleep issues. This highlights the need for routine screening and thorough evaluation of pilots and first officers who are at risk of OSA.

The overall prevalence of OSA in the Saudi population is $8.8 \%(12.8 \%$ in men and $5.1 \%$ in women $),{ }^{6}$ which is far lower than the $69.2 \%$ detected in our study population. Furthermore, the risk of OSA among pilots in Saudi Arabia was assessed by Aljurf et $\mathrm{al}^{7}$ with the Berlin 
questionnaire, and $29.3 \%$ of the pilots were at high risk of OSA. This may be due to difference in the sample size. ${ }^{7}$

A few studies have suggested that weight gain and sleep disturbances could have effects without actually using a validated questionnaire or an objective test to screen for OSA. In Brazil in 2016, Magna Lucia and his group reported the prevalence of overweight and obesity among pilots to be $53 \%$ and $14.6 \%$, respectively. Risk factors for obesity included working night shifts for 6-10 years, having difficulty relaxing after work, sleeping $<6$ $\mathrm{h}$ on days off, having other coexisting medical problems, and engaging in $<150 \mathrm{~min} /$ week of physical exercise. ${ }^{4}$

Excess body weight is an important predictor of the severity of blood oxygen desaturation during apnea and hypopnea events, potentially exacerbating the impact of sleep-disordered breathing in obese patients. ${ }^{21}$

This was consistent with our results, which showed a significant correlation between BMI and the number of desaturations.

One-third (33.3\%) of the participants had severe fatigue according to the FSS, and it is well known that fatigue is a common complaint among aircrew members. Although sleepiness and fatigue were observed in our study, they might have been underestimated due to the small sample size or underreporting of the symptoms by the participants. Reis et $\mathrm{al}^{3}$ reported a higher prevalence of sleepiness $(59.3 \%)$ and fatigue $(90.6 \%)$ among 435 pilots. This variation in the prevalence of such conditions warrants a more systemic screening of all crew members for the detection of these disorders. Education and awareness strategies should be implemented to decrease the burden of sleepiness and fatigue on those populations. Regulatory authorities may need to implement strict rules to ensure the safety of aircrew members by regulating their working hours.

Other relevant sleep history parameters that may be a consequence of sleep apnea in some cases are insomnia and depression, which were identified in $30.8 \%$ and $35.9 \%$ of the enrolled participants, respectively. In our study, the proportion of pilots who had scores consistent with depression was similar to that found by AlJurf et $\mathrm{al}^{7}$ and almost three times that reported in a cross-sectional study based on an anonymous web-based survey that found that $12.6 \%$ of airline pilots had depression and $4.1 \%$ of pilots had suicidal thoughts. ${ }^{22}$

The main limitation of our study is the small sample size. Not all pilots agreed to participate in the sleep study. The hesitation regarding participation could be related to concerns about job security and how the results could affect their promotion and future rank.

The Federal Aviation Administration requires medical examiners to routinely screen aircrew members for the risk of OSA and, if necessary, to refer them to their treating providers, who should then apply the Academy of Sleep Medicine clinical practice guidelines to determine whether further assessment, such as a sleep study, is clinically indicated. $^{23}$

In Saudi Arabia, aviation services currently follow the General Authority of Civil Aviation guidelines, in which screening pilots for OSA is not mandatory but is rather dependent on physician judgment.

\section{Conclusions}

Sleep apnea is prevalent among the studied Saudi-based airline pilots and first officers; however, the pilots and first officers do not frequently report daytime sleepiness. Thus, sleep apnea screening for all pilots and air traffic controllers should be considered. Unfortunately, subjective assessments with questionnaires were shown to be less accurate than objective HSAT, as substantial discrepancy between the subjective and objective assessments was noticed. Fatigue, depression, and insomnia can be secondary consequences of sleep apnea and should be assessed and treated early.

Further studies using objective assessments on a large scale are needed to evaluate sleep disorders among individuals with high-risk occupations to ensure the safety of all involved.

\section{Abbreviations}

AIS, Athens insomnia scale; ESS, Epworth sleepiness scale; FSS, fatigue severity index; GCC, gulf cooperation council; PHQ, patient health questionnaire; PSQI, Pittsburgh sleep quality index.

\section{Data Sharing Statement}

Raw data were generated at Sleep Medicine and Research Center, King Abdulaziz University Hospital, Jeddah, Saudi Arabia. Derived data supporting the findings of this study are available from the corresponding author F.H on request.

\section{Ethics Approval and Informed Consent}

The Unit of Biomedical Ethics of King Abdulaziz University Hospital reviewed and approved the research 
plan and its implementation. All procedures performed in studies involving human participants were in accordance with the ethical standards of the institutional and/or national research committee and with the 1964 Helsinki declaration and its later amendments or comparable ethical standards. Informed written consent was obtained from all participants prior to the commencement of the study.

\section{Consent for Publication}

The Authors transfer to the publisher the non-exclusive publication rights and he warrants that their contribution is original and that they have full power to make this grant. The corresponding author signs for and accepts responsibility for releasing this material on behalf of any and all co-authors. This transfer of publication rights covers the non-exclusive right to reproduce and distribute the article, including reprints, translations, photographic reproductions, microform, electronic form (offline, online) or any other reproductions of similar nature.

\section{Acknowledgments}

We are grateful to the participants of the study. The authors extend their appreciation to the Deanship of Scientific Research (DSR) at King Abdulaziz University for funding this work under grant no. (RG-2-I40-40). We would like to acknowledge the substantial efforts made by Mrs. Walaa Abuzahra, Research Coordinator, Sleep Medicine and Research Center, with regard to coordinating all study procedures.

\section{Author Contributions}

All authors contributed to data analysis, drafting or revising the article, have agreed on the journal to which the article will be submitted, gave final approval of the version to be published, and agree to be accountable for all aspects of the work.

\section{Funding}

This project was funded by the Deanship of Scientific Research (DSR) at King Abdulaziz University, Jeddah, under grant no. (RG-2-140-40). The authors, therefore, acknowledge the technical and financial support received from the DSR.

\section{Disclosure}

Mr Seithikurippu R. Pandi-Perumal report non-financial support from Somnogen Canada Inc., personal fees from Editorial work, during the conduct of the study. The authors report no other conflicts of interest in this work.

\section{References}

1. Heffron TM. Sleep loss contributed to plane crash that killed five. Available from: http://www.sleepeducation.org/news/2014/10/22/ sleep-loss-contributed-to-plane-crash-that-killed-five. Accessed April 19, 2021.

2. FAA. Fact Sheet-Sleep Apnea in Aviation. United States: Federal Aviation Administration; 2015.

3. Reis C, Mestre C, Canhão H, Gradwell D, Paiva T. Sleep complaints and fatigue of airline pilots. Sleep Sci. 2016;9(2):73-77. doi:10.1016/ j.slsci.2016.05.003

4. de Souza Palmeira ML, Cristina Marqueze E. Excess weight in regular aviation pilots associated with work and sleep characteristics. Sleep Sci. 2016;9(4):266-271. doi:10.1016/j. slsci.2016.12.001

5. Ruskin KJ, Caldwell JA, Caldwell JL, Boudreau EA. Screening for sleep apnea in morbidly obese pilots. Aerosp Med Hum Perform. 2015;86(9):835-841. doi:10.3357/AMHP.4163.2015

6. Wali SO, Abalkhail B, Krayem A. Prevalence and risk factors of obstructive sleep apnea syndrome in a Saudi Arabian population. Ann Thorac Med. 2017;12(2):88-94. doi:10.4103/1817-1737.2 03746

7. Aljurf TM, Olaish AH, BaHammam AS. Assessment of sleepiness, fatigue, and depression among Gulf cooperation council commercial airline pilots. Sleep Breath. 2018;22(2):411-419. doi:10.1007/ s11325-017-1565-7

8. Panton S, Norup PW, Videbaek R. Case report: obstructive sleep apnea-an air safety risk. Aviat Space Environ Med. 1997;68 (12):1139-1143.

9. Ahmadi N, Chung SA, Gibbs A, Shapiro CM. The Berlin questionnaire for sleep apnea in a sleep clinic population: relationship to polysomnographic measurement of respiratory disturbance. Sleep Breath. 2008;12(1):39-45. doi:10.1007/s11325-007-0125-y

10. Netzer NC, Stoohs RA, Netzer CM, Clark K, Strohl KP. Using the Berlin questionnaire to identify patients at risk for the sleep apnea syndrome. Ann Intern Med. 1999;131(7):485-491. doi:10.7326/00034819-131-7-199910050-00002

11. Johns MW. A new method for measuring daytime sleepiness: the Epworth sleepiness scale. Sleep. 1991;14(6):540-545. doi:10.1093/ sleep/14.6.540

12. Buysse DJ, Reynolds CF, Monk TH, Berman SR, Kupfer DJ. The Pittsburgh sleep quality index: a new instrument for psychiatric practice and research. Psychiatry Res. 1989;28(2):193-213. doi:10.1016/0165-1781(89)90047-4

13. Krupp LB, LaRocca NG, Muir-Nash J, Steinberg AD. The fatigue severity scale. Application to patients with multiple sclerosis and systemic lupus erythematosus. Arch Neurol. 1989;46 (10):1121-1123. doi:10.1001/archneur.1989.00520460115022

14. Shahid A., Wilkinson K., Marcu S., Shapiro C.M. (2011) Visual Analogue Scale to Evaluate Fatigue Severity (VAS-F). In: Shahid A., Wilkinson K., Marcu S., Shapiro C. (eds) STOP, THAT and One Hundred Other Sleep Scales. Springer, New York, NY. https://doi. org/10.1007/978-1-4419-9893-4_100Available from: https://geriatric toolkit.missouri.edu/fatigue/Fatigue-Severity-Scale.pdf. Accessed April 19, 2021.

15. Kroenke K, Spitzer RL, Williams JB. The PHQ-9: validity of a brief depression severity measure. J Gen Intern Med. 2001;16(9):606-613. doi:10.1046/j.1525-1497.2001.016009606.x

16. Papers and Publications. Search for SOMNOmedics papers \& publications below. Available from: https://somnomedics.de/en/com pany-eu/papers-and-publications. Accessed April 19, 2021.

17. Berry RB, Albertario CL, Harding SM, et al. The AASM Manual for the Scoring of Sleep and Associated Events: Rules, Terminology and Technical Specifications. Darien, IL: American Academy of Sleep Medicine; 2018. 
18. American Academy of Sleep Medicine. The International Classification of Sleep Disorders. Darien: American Academy of Sleep Medicine; 2014.

19. Hudgel DW. Sleep apnea severity classification - revisited. Sleep. 2016;39(5):1165-1166. doi:10.5665/sleep.5776

20. Khaledi-Paveh B, Khazaie H, Nasouri M, Ghadami MR, Tahmasian M. Evaluation of Berlin questionnaire validity for sleep apnea risk in sleep clinic populations. Basic Clin Neurosci. 2016;7 (1):43-48.

21. Peppard PE, Ward NR, Morrell MJ. The impact of obesity on oxygen desaturation during sleep-disordered breathing. Am J Respir Crit Care Med. 2009;180(8):788-793. doi:10.1164/rccm.200905-0773OC
22. Wu AC, Donnelly-McLay D, Weisskopf MG, McNeely E Betancourt TS, Allen JG. Airplane pilot mental health and suicidal thoughts: a cross-sectional descriptive study via anonymous web-based survey. Environ Health. 2016;15(1):121. doi:10.1186/ s12940-016-0200-6

23. AMAS. Sleep apnea. Available from: https://www.aviationmedicine. com/article/sleep-apnea/. Accessed April 19, 2021.

\section{Publish your work in this journal}

Nature and Science of Sleep is an international, peer-reviewed, open access journal covering all aspects of sleep science and sleep medicine, including the neurophysiology and functions of sleep, the genetics of sleep, sleep and society, biological rhythms, dreaming, sleep disorders and therapy, and strategies to optimize healthy sleep.
The manuscript management system is completely online and includes a very quick and fair peer-review system, which is all easy to use. Visit http://www.dovepress.com/testimonials.php to read real quotes from published authors. 